\title{
ОБМЕННЫЕ БАНКИ Р. ОУЭНА И НАРОДНЫЙ БАНК П.Ж. ПРУДОНА С ТОЧКИ ЗРЕНИЯ ТЕОРИИ НЕФИНАНСОВОЙ ЭКОНОМИКИ
}

\section{(c) 2021 Будович Юлия Ивановна}

доктор экономических наук, доцент, профессор Департамента экономической теории Финансовый университет при Правительстве Российской Федерации, Россия, Москва

E-mail: JBudovich@fa.ru

ORCID: https://orcid.org/0000-0001-8691-947X

\section{(c) 2021 Будович Маргарита Сергеевна}

кандидат экономических наук, доцент Департамента экономической теории Финансовый университет при Правительстве Российской Федерации, Россия, Москва

E-mail: MSBudovich@fa.ru

ORCID: https://orcid.org/0000-0002-7234-1408

Статья посвящена анализу сущности платежно-кредитных систем Обменных банков Р. Оуэна и Народного банка П.-Ж. Прудона. На основе сравнения с современными сетями прямого многостороннего обмена доказывается, что соответствующие платежно-кредитные системы являются нефинансовыми и, следовательно, более эффективными, чем банкнотные платежно-кредитные системы той эпохи, опровергается традиционное представление о том, что отмена денег в стихийной экономике невозможна, а также о том, что введение товарообменных сетей Р. Оуэна и П.-Ж. Прудона означало замену одних посредников в товарном обмене (банкнот) другими (трудовыми марками, билетами обращения). Показано, что средством обращения в их безденежных системах товарообмена выступали сами товары, передаваемые обществу.

Ключевые слова: нефинансовая экономика, платежно-кредитная система, Обменные банки Оуэна, Народный банк Прудона, прямой многосторонний товарообмен.

Теория нефинансовой экономики (экономики без финансов), в рамках которой написана данная статья, исходит из того, что у всех финансовых, т.е. основанных на трансфертных сделках, систем ресурсобеспечения (налоговых, бюджетных, пенсионных, страховых и т.д.) есть нефинансовые, т.е. основанные на сделках купли-продажи, заменители, отмечает, что нефинансовые системы обеспечения («нефинансы») вытесняют финансовые системы («финансы»), поскольку являются более эффективными (более доступными, экономичными и безопасными), но этот процесс идет весьма нелинейно, прежде всего, в силу сопротивления, которое финансы оказывают развитию нефинансов.

Цель настоящей статьи - показать, что платежная и кредитная системы ресурсообеспечения, представленные в Обменных банках Р. Оуэна и Народном банке П.-Ж. Прудона, являются нефинансовыми и, следовательно, более эффективными (доступными, экономичными и безопасными), чем действовавшие в ту эпоху банковские банкнотные платежно-кредитные системы, являющиеся финансовыми системами, что, при прочих равных условиях, соответствующие безденежные платежно-кредитные системы должны были вытеснять традиционные банки, но развитие платежно-кредитных систем стран пошло по банковскому пути, что было обусловлено, прежде всего, противодействием процессу развития безденежного обмена со стороны финансов, а также показать неадекватность пришедших из советской науки положений о невозможности отмены денег в стихийной, в частности, в основанной на банкнотном обмене, экономике и о том, что введение товарообменных систем Р.Оуэна и П.-Ж. Прудона означало замену одних посредников в обращении товаров (денег) другими (трудовыми бонами, билетами обращения).

Первые две подцели предполагается достичь, показав соответствие предприятий Р.Оуэна и П.-Ж Прудона современным типам локальных товарообменных систем с нефинансовыми платежно-кредитными системами, возникшим в 1980-е гг. и приобретающим все большую по- 
пулярность. Ранее нами уже рассматривался один из таких типов на примере бартерной сети BizXchange Сиэтла. BizXchange - локальная система прямого многостороннего товарообмена (один из его участников, придорожный ресторан Pappy’s Place взамен на бесплатные обеды получал от сообщества множество товаров, например услуги по чистке снега и по предоставлению рекламных площадей), использующая в качестве знаков прав на получение товаров безналичные «торговые доллары», дающая и возможность получения товарного кредита (один из ресторанов получил разрешение на кредит на сумму 150 тыс. торговых долларов под 7,5\% годовых с возвратом десятью корпоративными вечеринками для участников системы стоимостью по 15 тыс. каждая) [4, с. 110]. Платежные системы локальных сетей прямого товарообмена (любого типа) трактуются теорией нефинансовой экономики как нефинансовые потому, что в них роль средства платежа играют предметы, внутренняя стоимость которых равна их номиналу, в данном случае переданные участниками сообщества другим его участникам товары. Заметим, что нефинансовые платежные системы могут быть не только безденежными, как прямой товарообмен, но и денежными, как, например, расчеты товарными деньгами (роль которых выполняли скот, меха, рабы и т.д.), полноценными монетами, расписками о приеме на хранение золота. Расчеты, в частности, банковскими наличными и безналичными деньгами трактуются как финансовые платежные системы, поскольку в них платежные средства не имеют внутренней стоимости, равной их номиналу. Кредитные системы локальных сетей прямого многостороннего товарообмена трактуются теорией нефинансовой экономики как нефинансовые потому, что участники системы получают товарный кредит от сообщества и возвращают его обществу товарами не на основании договоров кредита, а на основании договоров поставки товаров, т.е. участники системы, передающие товары заемщику и получающие от него товары даже не знают, что участвуют в кредитной операции.

Заметим, что участники систем прямого многостороннего товарообмена вместо того, чтобы получать от получателей своих продуктов деньги, а затем выменивать на эти деньги нужные им продукты у других участников обмена, получают эти продукты сразу в обмен на переданные обществу свои продукты, далее, вместо того, чтобы получать от банков кредиты деньгами и выменивать на них продукты, нужные для реализации инвестиционных проектов, а затем выменивать продукты реализованных проектов на деньги и возвращать ими кредиты банкам, сразу получают от общества кредиты товарами и возвращают их обществу сразу товарами.

Общим для функционирования локальных сетей прямого товарообмена любого типа является наличие: сообщества людей, договорившихся о взаимном прямом обмене товарами, меры стоимости, системы, обеспечивающей эквивалентность товарообмена между отдельным участником и остальным сообществом, оператора кредита, выдающего разрешения на получение товаров от общества в кредит при условии, что он будет возвращен обществу товарами, пользующимися спросом по соответствующей цене, а также крайне низкая стоимость предприятия оператора платежей и кредита (см. ниже). Для сетей типа рассмотренной выше биржи характерно установление цен (заметим, не входящее в функции собственно платежно-кредитной системы) на товары рыночным путем в порядке переговоров между поставщиком и получателем товара, а также наличие внешнего (не являющегося участником обмена) коммерческого оператора платежной и кредитной систем, бизнес которого не связан с бизнесом участников обмена.

Нами было отмечен рост в мире бартерного обмена всех типов, например, что в США доля бартера в товарообороте составляет 10\% и стремительно растет, причем в силу именно его большей приемлемости по сравнению с банковским товарообменом, а не, например, развития Интернета и компьютеризации бартера, поскольку цифровизация является вектором развития и банковского товарного обмена, да еще и не менее стремительного [4, с. 109]. Как выясняется, «новая» история локальных сетей прямого многостороннего товарообмена рассмотренного выше типа, называемого «LETS» (Local Employment and Trading Systems - система местной занятости и торговли), началась в 1983 г. в Канаде, где в провинции Ванкувер, население которой страдало от отсутствия денег для удовлетворения первоочередных нужд из-за резкого роста безработицы в результате массового закрытия рудников, безработный программист М.Линтон запустил первую такую систему [5, с. 62]. Волна широкого распространения LETS приходится на начало 1990-х гг. и связывается с 
глобализацией капитала, вымывающей деньги из местных экономик. Тогда эти системы появляются в США, Австралии, Новой Зеландии, Японии, Германии, Великобритании, Франции, Швейцарии и т.д., а с середины 1990-х гг.- в странах третьего мира (Мексике, Аргентине, Бразилии, Индонезии и т.д.) [5, с. 63].

Следует отметить и развитие в последние десятилетия такого типа локальных сетей прямого многостороннего товарообмена, как «банки времени», для которых характерно, прежде всего, использование в качестве меры стоимости товаров времени труда. Банк времени трактуется экспертами как общественная организация, занимающаяся учетом времени, потраченного ее членами на оказание волонтерской помощи друг другу. За каждый час волонтерского труда участнику системы зачисляется на счет в банке времени 1 кредит, который он может использовать на получение помощи от других участников системы. Банки времени также могут предоставлять своим участникам кредиты (займы) в товаpax - за помощью могут обращаться люди и вне зависимости от того, имеют они заработанные кредиты или нет [9].

Особенностью банков времени также является их нацеленность на решение социальных проблем и отношения сотрудничества между их участниками. Современный основатель банков времени американский правозащитник Э.Кан трактовал банки времени как средство решения социальных проблем в условиях, когда у государства нет денег на социальные программы, нацеленные на помощь, адаптацию и спасение социально неустроенных людей. При этом в основе деятельности банка времени лежат отношения сотрудничества и взаимопомощи, так как банк времени предполагает двухсторонние отношения: человек не только берет, но и дает взамен. Банки времени дают людям возможность выстраивать экономические отношения на принципах солидарности, равенства, взаимопомощи, сотрудничества, позволяют обходить главный закон рыночной экономики, а именно закон конкуренции, ставящий в основу отношений борьбу за ресурсы. Еще одной особенностью банка времени является ключевая роль в его успешном развитии координатора, связывающего членов банка между собой, определявшего стоимость товаров (в часах труда) и ведущего учет кредитов времени по приходу или расходу счетов участников [9], роль которого также могут выполнять наиболее активные участники сети [5, с. 62].

Появление банков времени относят к началу 1980-х гг. В 2005 г. в США было уже около 300 банков времени, а в Великобритании - 100 [9]. Самыми востребованными видами взаимопомощи в системах товарообмена, обслуживаемых банками времени, являются уборка и ремонт помещений, репетиторство, макияж и маникюр, услуги курьеров и водителей [5, с. 61]. При этом очередная волна развития как банков времени, так и LETS, а именно с 2008 г., связывается специалистами уже с опасениями очередной волны финансовоэкономического кризиса [5, с. 59].

Приведенные данные о начале очередного возрождения локальных систем прямого многостороннего товарообмена подтверждают высказанную нами мысль о том, что в последние десятилетия в мире идет повсеместный процесс вытеснения финансов нефинансами [10, с. 70].

Ранее мы уже объясняли тенденцию вытеснения бартером банковской платежнокредитной системы большей эффективностью первого в плане доступности, экономичности и безопасности для клиентов [4, с. 109], однако, не имея в виду конкретно его рассматриваемой сейчас разновидности. В связи с этим раскроем выгоды безденежного многостороннего обмена для его участников. Как платежная система он более доступен как источник платежных средств, так как для их получения клиенту достаточно передать обществу свой товар. Для получения платежных средств от денежной платежной системы нужно ждать оплаты товара получателем, появления денег у покупателей товара, если их у них нет на данный момент времени, ждать получения денег от кредитной системы после получения от нее разрешения на кредит. Безденежная платежная система является более дешевой, чем денежная, поскольку ее участнику нет необходимости вкладывать средства в денежные активы (расчетный счет, кассу и др.) и, следовательно, нести расходы по их содержанию. Безденежная платежная система является значительно более безопасной, так как денежные активы, которые участник обмена вынужден содержать при денежной системе, могут потерять ликвидность (заморозиться, обесцениться и т.д.) вследствие проблем, возникших у банка, и обесцениться вследствие инфляции. Прямой многосторонний товарообмен более доступен для его участников как кредитная система, так как выдача кредита теперь не зависит от финансового 
состояния банка, а зависит только от качества кредитуемого проекта. Услуги этой кредитной системы обходятся участникам обмена значительно дешевле, так как оператор кредита здесь не несет расходов по привлечению огромных ресурсов в виде собственного, привлеченного и заемного (в необходимых случаях) капитала, необходимых для осуществления кредитных операций банкам. Она менее опасна, чем денежная, так как дальнейший процесс кредитования не зависит от финансового состояния банка, который в соответствующих случаях может прекратить кредитование, повысить проценты за кредит и т.д.

Заметим, что безденежная платежнокредитная система более приемлема и для ее операторов. Она значительно более доступна ввиду отсутствия необходимости банковского лицензирования и, главное, вследствие крайне низкой стоимости предприятия (см. выше). Об этом говорит то, что запуск соответствующих сетей может осуществляться группами их активных членов на общественных началах [5, с. 63] и даже безработными (см. выше). Она более экономична в силу той же низкой стоимости предприятия. Она менее опасна ввиду отсутствия у ее операторов банковских рисков ликвидности и кредитных рисков.

Покажем, что система обменных банков (основу которых образовывали товарные склады) Р. Оуэна была прообразом современных банков времени. Прежде всего, как и банки времени, она была системой прямого, т.е. безденежного, многостороннего товарообмена, образованной на основе соглашения его участников. Как писал о создании обменных банков Р. Оуэна один из создателей советской теории денег и кредита 3.В.Атлас, в 1832 г. Р. Оуэн обратился от имени «Института справедливого обмена трудящихся классов» к широкой публике, предложив организовать обмен товарами так, чтобы каждый отдавал свою ценность, выраженную в труде, за равную ценность, выраженную в труде, без посредства денег [1, с. 194]. Отсюда также видно, что, как и в банках времени, в системе Р. Оуэна в качестве меры стоимости использовалось время труда. Как писал сам Р. Оуэн, мерилом ценности товаров является время, причем 1 час работы равен 6 пенсам [15, с. 307]. Продажная цена любого предмета определяется путем прибавления труда или стоимости времени к стоимости (рыночной цене) материалов [15, с. 309]. Заметим, что приравнивание часов труда к некоторому количеству национальных денег представлено и в современных банках времени, например, таковыми являются трудовые деньги Ithaca hours [3].

Как и банки времени, предприятие Р. Оуэна создавалось для решения «социального вопроса», в данном случае поддержки простых товаропроизводителей и обеспечения получения ими полной стоимости своих товаров (см. ниже). При этом, как и банк времени, обменные банки рассматривались их основателем как система сотрудничества, а не соперничества [15, с. 305].

Как и в работе банков времени, в обеспечении успешного функционирования предприятия Р. Оуэна ключевую роль играл координатор, которыми выступали склады, выполнявшие функции координатора банков времени. Склады соединяли вместе участников системы, принимая товары от производителей и выдавая их потребителям, а также предоставляя сведения об избыточных запасах, имеющихся на складах предприятий, и о предметах, которые им требуются [15, с. 305]. Склады определяли стоимость товаров - на основе предоставленных производителями данных о себестоимости сырья и о времени, затраченном на производство готового товара, производили оценку товара в часах труда [15, с. 312]. Они фактически организовывали учет кредитов времени, получаемых и расходуемых участниками системы, выдавая сдавшим товары на склады бумажные боны (выпускались номиналом 1, 2, 5, 10, 20, 50 и 100 часов) на сумму оценки товара $[15$, с. 312] и принимая их от взявших товары со складов на сумму оценки последних. В связи с этим лица, передавшие товары обществу, не могли получить от него больше товаров, чем передали ему, так как невозможно израсходовать бонов больше, чем имеется на руках. Следует отметить, что такой, а именно наличный, способ учета получения и расходования кредитов времени был обусловлен господством в то время наличных бумажных банковских денег (банкнот), хотя банки уже производили безналичные расчеты, например для этого были созданы Банк Сан-Джорджо (1444) и Банк ди Риальто (1638) [14, с. 108], так что Р. Оуэн вполне мог организовать и систему безналичного учета приобретения и расходования прав на получение товаров от общества участниками его товарообменной сети.

Предприятие Р. Оуэна также выдавало товарные кредиты его участникам. Так, М.И.Туган- 
Барановский характеризует предприятие Р. Оуэна как банк в Лондоне, который ссужал производителей под залог товаров «рабочими марками», выражавшими количество труда, потраченное на производство товаров [13]. Следует отметить, что кредитная операция сети Р.Оуэна в действительности была значительно шире, так как главными заемщиками товаров в сети были сами склады, получавшие товарный кредит от сети, принимая товары ее участников на комиссию, и погашавшие его, передавая товары со складов нуждающимся в них участникам сети. При этом склады должны были получать трудовые боны для выдачи поставщикам товаров на склады от кредитного оператора, а полученные от получателей товаров боны - возвращать кредитному оператору в подтверждение погашения товарного кредита.

Обменные банки Р.Оуэна, таким образом, были аналогом современных банков времени (с той разницей, что обмен в сети Р. Оуэна осуществлялся преимущественно продукцией через централизованные склады, а эквивалентность товарного обмена участников с сообществом обеспечивалась с помощью наличных знаков прав на получение товаров). Это говорит о том, что обменные банки Р. Оуэна имели в своей основе нефинансовую платежно-кредитную систему, более эффективную, чем банковская платежно-кредитная система, представлявшую все рассмотренные выше преимущества для ее участников и операторов, включая дешевизну использования, обусловленную низкой стоимостью предприятия оператора. И на самом деле, нет сведений, чтобы Обменные банки Р. Оуэна в период основания решали проблему высокой стоимости предприятия-оператора. В связи с отмеченным выше, локальные товарообменные сети типа предприятия Р. Оуэна, могли, подобно современным банкам времени, успешно развиваться в условиях такой же, как и сейчас, стихийной экономики, вытесняя банковскую систему.

Интересно, что Р.Оуэн, в полном соответствии с теорией нефинансовой экономики, конкретизирует полезность своего «нефинансового» предприятия для клиентов в терминах его большей доступности, экономичности и безопасности. Предлагаемая товарообменная сеть более доступна как платежная система - получение расчетных средств зависит от решения самого производителя, а не от благосклонности посредников и наличия в экономике денег: «Вместо того чтобы человек, как это бывает теперь, ждал, когда он получит работу, чтобы приобрести нужные ему вещи, он должен будет только работать, сложить на склад свою продукцию и тотчас сумеет получить то, что ему надо... Ведь сейчас наблюдается такая аномалия, что производитель выпускает изобильную продукцию, окружен как бы избытком ее и в то же время не может помочь собственной беде» [15, с. 302-303].

Предлагаемая сеть, в данном случае в части обмена через комиссионные склады и наличия личных связей, более экономична. При нынешней системе, как пишет Р. Оуэн, «...производитель полностью зависит от посредника, который всегда бывает в выигрыше, так как удерживает с каждого продукта, проходящего через его руки, часть в свою пользу; это причиняет явный ущерб производителю, который продает свою продукцию с потерей и приобретает чужую по повышенной цене. / Теперь эти посредники больше не нужны, производители могут обойтись без них, им надо только вступить в общение друг с другом, и они сумеют обменивать друг у друга свою продукцию к взаимной выгоде...» [15, с. 301-302].

Предлагаемая сеть менее токсична (опасна), так как исключает следующую ситуацию, характерную для банковской платежной системы и посреднической торговли: «Если наблюдается недостаток денег или если посредник не склонен приобрести предлагаемый продукт, то производитель должен пойти на существенные жертвы для достижения своей цели в виде уступки более значительной части своей продукции для получения требуемых ему предметов...» [15, с. 301].

Покажем, что Народный банк идеолога анархизма Пьера-Жозефа Прудона (1809-1865) был прообразом современных локальных товарообменных сетей типа LETS. Прежде всего, как и LETS, он был системой прямого, т.е. безденежного, многостороннего товарообмена, образованной на основе соглашения его участников. Как писал М.И. Туган-Барановский, банк П.-Ж. Прудона должен был обслуживать общество производителей товаров всякого рода, члены которого обмениваются производимыми продуктами друг с другом [13]. Членами такого общества и становились учредители банка. Согласно уставу, каждый член общества («Общества народного банка») обязуется забирать все предметы, необходимые для его потребления и давать заказы исключительно членам общества, и этот взаимный обмен услуг и труда будет обслуживаться 
билетами обращения. Список участников общества с обозначением их занятий и мест жительства будет постоянно вывешиваться в конторах общества [2, с. 405-406].

У товарообменной сети П.-Ж. Прудона был независимый внешний организатор платежной и оператор кредитной системы, никак не связанный с участниками сети, как в банках времени и Обменных банках Р. Оуэна. В уставе специально подчеркивается, что банк не имеет никакого отношения к делам участников товарообмена ни в коем случае. Так, отмечается, что, в целях введения в обращение билетов банка, учредители общества озаботятся об открытии булочных, молочных лавок и других торговых и промышленных заведений для удовлетворения первых насущных потребностей в обмен на билеты обращения, но эти учреждения должны быть совершенно самостоятельны относительно банка [2, с. 407].

Банк П.-Ж. Прудона не вмешивался и в вопросы ценообразования, которое в сети было рыночным, хотя в уставе банка и было записано условие доставлять товары по возможно дешевой цене и на возможно выгоднейших условиях [2, с. 407], и, соответственно, кредитные билеты Народного банка, именуемые билетами обращения, были номинированы во франках (выпускались 5, 10, 20, 50 и 100-франкового достоинства) [2, c. 403-404].

Кредитование (точнее, выдача разрешений на получение товаров в кредит от общества и контроль за погашением товарных кредитов), судя по уставу, выглядело как главное направление деятельности Народного банка. Он осуществляет учет (торговых) векселей, выдает ссуды под коммандиты и фактуры, выдает ссуды под депозиты и кредиты под поручительство. При этом Народный банк весьма осмотрителен в кредитной политике. Так, права на получение товаров от общества (в виде билетов обращения) выдавались клиентам под уже переданные ими товары обществу в форме учета торговых векселей, под гарантированные обязательства, например коллективные обязательства рабочих ассоциаций [2, с. 406]. Ссуда банка под товары представляла их покупку за $1 / 2,1 / 3$ и даже за $1 / 4$ и 1/5 от цены на срок, по истечении которого банк выставляет их на продажу на общественном складе или в магазине [2, с. 410], что гарантировало возврат товарных кредитов обществу заемщиками (их покупку по соответствующим ценам). Заметим, что здесь банк П.-Ж. Прудона вынужденно выступал перекупщиком товаров, подобно складам Р. Оуэна.

В уставе банка П.-Ж. Прудона обращается внимание на крайне низкую стоимость предприятия-оператора. Банк «может и должен действовать без капитала», но образует капитал, подчиняясь общему закону [2, с. 401-402], очевидно об акционерных обществах, и в особенности желая побудить граждан принять участие в банке [2, с. 402], а точнее - в прямом многостороннем товарообмене, а это участие могло быть обеспечено только покупкой гражданами акций, что означает образование собственного капитала банка.

Отличием банка П.-Ж. Прудона от современных локальных безденежных товарообменных сетей был архаичный способ обеспечения эквивалентности товарообмена между участниками и остальным обществом, как и в сети Р. Оуэна осуществлявшийся с помощью наличных бумажных знаков прав на получение товаров (билетов обращения), обязательно передававшихся другой стороне сделки взамен полученных товаров, уступленных ей товарных прав и погашенного товарного кредита.

Банк П.-Ж. Прудона, таким образом, был аналогом современных локальных сетей безденежного обмена типа LETS. Это говорит о том, что он имел в своей основе нефинансовую платежно-кредитную систему, более эффективную, чем банковская платежно-кредитная система. Поэтому локальные товарообменные сети типа Народного банка, подобно современным сетям типа LETS, могли успешно развиваться, вытесняя банковскую систему, в условиях такой же стихийной экономики.

Проект Р. Оуэна, как известно, заработал, но в итоге потерпел крах. Его склады, или «рабочие базары», были основаны кооперативными обществами рабочих в разных городах Англии, причем первый из них был основан самим Р. Оуэном в Лондоне в сентябре 1832 г., просуществовав до середины 1834 г. [16]. Как писал 3. В.Атлас о печальной судьбе предприятия Р. Оуэна, базары первоначально имели большой успех. Институт справедливого обмена за посредничество в обмене даже брал по 8 1/3\% с каждой операции. Однако, через несколько лет предприятие лопнуло, так как производство товаров не регулировалось и оставалось анархическим, а Институт принимал все продукты, на которые был за- 
трачен труд. Кроме того, обмен основывался на произвольных расчетах оценщиков, не имевших возможности ни учесть условия производства, ни общественные потребности, что достижимо лишь при всеобщей плановой организации общественного производства [1, с. 194].

М.И.Туган-Барановский, объясняя крах Обменных банков, писал, что в условиях неорганизованности общественного производства рабочая биржа Р.Оуэна стояла перед альтернативой: принимать только такие товары, на которые имелся спрос, и по той цене, по которой покупатели захотели бы их купить - но в таком случае биржа не удовлетворяла бы своему назначению - обеспечить сбыт всех товаров по их трудовой стоимости. Удовлетворяя же ему, рабочая биржа без разбора принимала всякие товары по их трудовой стоимости, не имея возможности сбыть товары за отсутствием на них спроса. В результате рабочая биржа Р. Оуэна просуществовала лишь около двух лет, благодаря денежной поддержке со стороны, но в итоге ликвидировала свои дела с большим убытком [17, с. 99-100]. В другой своей работе М.И. Туган-Барановский пишет о судьбе предприятия Р.Оуэна следующее. Первоначально банк имел успех, рабочие марки охотно принимались вместо денег, и даже лондонские театры открыли для них свои кассы. Предприятие же лопнуло потому, что рабочие были недовольны теми товарами, которые банк предлагал им на продажу. Курс марок постоянно падал, в связи с чем банк прекратил их выпускать и ликвидировал свои дела [13].

Банк П-Ж. Прудона также пользовался огромным успехом среди широких масс народа, который он, правда, смог продемонстрировать только на стадии формирования. Как пишет М.И Туган-Барановский, число акционеров банка достигало 12 тыс. Идея Народного банка находила широкую поддержку не только в Париже, но и в провинции [13]. К сожалению, банк П.-Ж. Прудона реально не заработал. Он был учрежден 31 января 1849 г., а 28 марта 1849 г. П.-Ж. Прудон был предан суду присяжных за две статьи против Луи Бонапарта, приговорен к 3000 франков штрафа и 3 годам тюрьмы. 11 апреля П.-Ж. Прудон объявил в своей газете, что приостанавливает свое предприятие [11].

Раньше в печальной судьбе рассмотренных выше социалистических проектов усматривали подтверждение нежизнеспособности товарообменных сетей подобного рода в стихийной эко- номике, и такая оценка неизбежно распространялась на эффективность их платежно-кредитных систем. Теперь, на примере современных банков времени и LETS, мы видим, что их судьба таким подтверждением не является. Это, прежде всего, побуждает искать в истории экономики другие, более удачные примеры функционирования подобных систем товарообмена. Банк времени Р.Оуэна был не единственной попыткой создания банков времени в ту эпоху, и, возможно, экономическая история установит даже массовость подобного явления. И уже выясняется, что в 1827 г. американский анархист и последователь Р. Оуэна Джосайя Уоррен в г. Цинцинатти создал обменный банк Time Store, просуществовавший целых три года. При оценке товара при его сдаче в магазин учитывалось время не только на изготовление товара, но и на его доставку, а при его передаче покупателю еще и учитывалось время, в течение которого покупатель общался с продавцом. На руки выдавались трудовые боны в виде обязательств отработать соответствующее количество времени, либо вернуть его кукурузой по курсу 12 фунтов за час труда, которые вначале были именными, а потом стали выпускаться на предъявителя [3]. Сам критик системы П.Ж. Прудона М.И. Туган-Барановский приводит примеры длительного успешного функционирования локальных сетей прямого товарообмена типа Народного банка, правда, активно использующих товарные комиссионные склады. Это меновой банк Мацеля (П.-Ж. Прудона даже обвиняли в том, что он украл идею банковской реформы у Мацеля), просуществовавший 16 лет в Марселе и закрывшийся за несколько лет до февральской революции во Франции (очевидно, революции 1848 г.- примеч. авт.) по той же причине скопления непроданных товаров, далее, меновой банк Боннара, открытый в Марселе в 1849 г. и просуществовавший 10 лет, закрывшийся в результате судебного процесса, инициированного одним из клиентов банка за то, что в обмен на его доброкачественный товар ему дали никому не нужную залежь [17, с. 100-101]. М.И. Туган-Барановский приводит данные даже о необычной успешности операторов этих сетей как коммерческих предприятий, в частности того же менового банка Боннара, который выдавал ремесленникам нужные им материалы под их обязательства доставить банку продукцию их производства лишь в случае, если был уверен в наличии на нее хорошего спроса. Основанный с 
капиталом всего 2,5 тыс. руб. (во франковом эквиваленте), он уже в первый год существования достиг оборота в 250 тыс. руб., получив чистую прибыль 4325 руб., или 173\% годовых на вложенный капитал, а в 1852 г. его чистая прибыль составила уже 38 тыс. руб. [13].

Средний срок жизни четырех рассмотренных выше реально действовавших сетей прямого товарообмена составил 7,75 лет $((2+3+16+10) / 4)$. Не эта ли цифра является лучшим подтверждением их большей жизнеспособности, а заодно и большей эффективности их платежно-кредитных систем, по сравнению с товарообменом на основе банковских денег и банковской платежнокредитной системой в соответствующую историческую эпоху, если нам известно, что в США в 1837-1862 гг., т.е. в период свободной банковской деятельности, средний срок жизни банка составлял 5 лет [14, с. 71], т.е. был более чем в полтора раза короче $(7,75 / 5=1,55)$.

Теория нефинансовой экономики объясняет нелинейность вытеснения сетями прямого товарообмена банковского товарообмена, включая платежно-кредитную систему последнего, противодействием, которое банковская система оказывает развитию сетей прямого товарообмена. Без этого противодействия развитие платежно-кредитных систем стран могло с самого начала пойти по пути формирования общенациональных сетей прямого товарообмена на основе локальных сетей и даже безналичного учета прав на получение товаров. В средние века, еще до появления банковских денег, в странах активно функционировали временные локальные сети многостороннего безденежного товарообмена с безналичным учетом товарных расчетов, создававшиеся при ярмарках, от которых мог бы начать отсчет процесс создания соответствующих общенациональных систем. На наш взгляд, крест на пути развития безденежного обмена в обществе был поставлен тогда, когда было установлено, что распространение финансовых платежных средств является высокоприбыльным бизнесом. Внедрение бумажных правительственных денег приносило государству с его хроническим дефицитом бюджета значительный доход. Внедрение банкнот приносило доход банкам, так как оно происходило в порядке выдачи кредитов под проценты. При этом банки сделали участниками этого бизнеса и население, так как еще больше банкнот можно было выпустить, привлекая во вклады драго- ценные металлы населения под определенный процент. C «захватом» банками драгметаллов населения заинтересованной в распространении банковских денег стала и соответствующая часть населения. Главным средством агитации за использование банкнот стала надпись на них о свободном размене на золото или серебро по номиналу на предъявителя. Для ее воздействия на людей золото и серебро стали воспеваться как истинное богатство. В создании банковских денег было заинтересовано государство, так как оно могло заставить банки выдавать ему кредиты полученными во вклады металлами. Если бы не дефицит госбюджета и не проценты по кредитам, выступающие явлениями финансового мира, временные сети прямого многостороннего обмена при ярмарках могли бы превратиться в постоянные местные сети, а центральный банк мог бы возникнуть как центр межсетевых товарных расчетов.

Сказанное выше об успешности локальных сетей типа обменных банков Р.Оуэна и банка П.-Ж. Прудона в стихийной экономике говорит о неадекватности пришедшего из советской науки положения о невозможности отмены денег в стихийно экономике, которое подтверждалось судьбой проектов этих социалистов. Как писал 3.В.Атлас, «...поскольку существует рынок, и производство регулируется не сознательно, а стихийно, постольку необходимо существование денег» [1, с. 195]. Кстати, эту точку зрения первоначально отстаивал и К. Маркс. В «Критике политической экономии» (написано в 1859 г.) он критикует проект английского социалиста Джона Грея по замене в буржуазном обществе денег «рабочими деньгами», утверждая, что этого нельзя сделать без замены всех остальных условий буржуазного производства, и в доказательство этого К. Маркс отмечает, что к такой замене незаметно для самого себя склоняется сам Грей. Как пишет К. Маркс, «...если внимательно приглядеться к деятельности его банка, то можно обнаружить, что он не только одной рукой принимает товары, а другой выдает свидетельства на доставленный труд, но и регулирует самое производство» [12, с. 69]. Обнаружив, что банки времени успешно действуют в современной рыночной экономике, теперь уже нельзя согласиться с тем, что весь выпущенный товар в стихийной экономике может быть реализован только по цене спроса на это количество товара, которая совпадает с индивидуальными затрата- 
ми труда лишь случайно. Следует отметить, что цена товара в сети Р. Оуэна в части добавленной стоимости фактически устанавливалась в среднечасовой зарплате, равной 6 пенсам [15, с. 307], которая могла быть значительно ниже добавленной стоимости в его рыночной цене, в связи с чем трудовая цена могла обеспечивать величину спроса, соответствующую произведенному количеству товара. Представляется, что истинной причиной краха предприятия Р. Оуэна стало мошенничество, а не, например, то, что, как отмечал 3.В.Атлас, производившийся обмен основывался на произвольных расчетах оценщиков (см. выше). Приемка и оценка товаров осуществлялась на основе данных об их нужности обществу и о затратах труда и материалов на их изготовление, предоставлявшихся сдатчиками товаров, т.е., как писал Р. Оуэн, в основе работы сети лежали «чистейшая добросовестность и чувство чести» [15, с. 305]. И, как выясняется, предприятие подверглось атаке мошенников, которые стали сбрасывать на склады залежалые и не находившие спроса товары, и в обмен на полученные боны тут же забирать со складов ходовые товары для их перепродажи за деньги [3].

Введение товарообменных сетей Р. Оуэна и П.-Ж. Прудона с их платежно-кредитными системами вполне обоснованно трактуется в экономической литературе как отмена денег или денежного обращения. Так, в учебниках Р. Оуэн характеризуется как социалист, считавший необходимым отмену денег [6], ученый, пришедший к выводу, что, поскольку, благодаря деньгам, жажда прибыли подчиняет себе обмен, в связи с чем становится возможной продажа товара по цене выше себестоимости, деньги нужно ликвидировать [7], план П.-Ж. Прудона по введению билетов обращения трактуется как ликвидация денег [8], отмечается, что П.-Ж. Прудон выдвинул утопический проект безденежного товарного хозяйства [18]. Однако ликвидация денег Р. Оуэном и П.-Ж. Прудоном зачастую трактуется как их замена «неденежными» посредниками в товарном обмене, в то время как введение их товарообменных систем в действительности означало переход к многостороннему товарообмену без всяких посредников. Такая трактовка была характерна и для выдающихся ученыхэкономистов. Так, М.И. Туган-Барановский, рассматривая систему Р. Оуэна, соглашается с тем, что ее введение означало замену денег в качестве меновых посредников просто бумажными знаками, отмечает, имея в виду и банк П.-Ж. Прудона, что невозможно обеспечить сбыт всех товаров путем замены денег какими-либо условными знаками [17, с. 99-100].

При этом в трактовке ликвидации денег как замены их неденежными посредниками в товарообмене виноваты сами Р.Оуэн и П.-Ж. Прудон. Так, Р. Оуэн трактовал свои трудовые боны как новое мерило ценности и средство обращения, как средство, заменяющее в этих функциях традиционные деньги [15, с. 295], хотя мерилом ценности у него реально был труд, а средством обращения - сами товары. В уставе банка П.-Ж. Прудона выпускаемый им билет обращения рассматривается как заменитель обычных кредитных билетов, отличающийся от последних тем, что разменивается не на звонкую монету, а на произведения труда членов общества [2, с. 404].

\section{Библиографический список}

1. Атлас 3. В. Деньги и кредит (при капитализме и в СССР) - М. - Л.: Государственное издательство, 1930. 459 c.

2. Бехер Э. Рабочий вопрос в его современном значении и средства к его разрешению с приложением уставов народного банка Прудона и уставов международной ассоциации рабочих / Под ред. П.Н. Ткачева.- СПб.: Издание книжного магазина Черкесова, 1869-1871. 460 (VIII) с.

3. Бондарь Д. Труд как ценность: классические проекты трудовых денег и современность / forklog. 29.11.2016. URL: https://forklog.com/trud-kak-tsennost-klassicheskie-proekty-trudovyh-deneg-i-sovremennost/ (дата обращения: 23.03.2021).

4. Будович Ю.И., Лебедев К. Н. Место финансов в современной экономике (Экономика без финансов) / под ред. К.Н. Лебедева.- Краснодар: Издательство НИИ экономики ЮФО, 2020. 187 с.

5. Воловодова Е. В. Опыт использования локальных систем обмена услугами и товарами в кризисных условиях // Вестник Института экономических исследований. 2016. № 2. С. 58-65.

6. Всеобщая история: учебник для 8 класса. § 9-10. Либералы, консерваторы и социалисты: каким должно быть общество и государство / www.tepka.ru. URL: https://tepka.ru/vseobschaya_istoriya_8/9.html (дата обращения: 06.02.2020). 
7. Как определял Р. Оуэн экономические категории «стоимость», «прибыль», «деньги»? / Studbooks.net. URL: https://studbooks.net/37830/politekonomiya/ouen_ekonomicheskie_kategorii_stoimost_pribyl_dengi (дата обращения: 06.02.2021).

8. онцепция реформ П.Прудона / Студопедия. 20.04.2015. URL: https://studopedia.ru/8_43229_kontseptsiyareform-p-prudona.html (дата обращения: 06.02.2021).

9. Кроль М. Банки времени / CLOUDWATCHER. Лаборатория социальных инноваций. URL: http://cloudwatcher. ru/what-we-think/3/ (дата обращения: 24.03.2021).

10. Лебедев К.Н. Соглашение государства с бизнесом о добровольном финансировании социальных проектов из сверхдоходов как новый и перспективный институт нефинансовой экономики // бизнес. Образование. Право. Вестник Волгоградского института бизнеса. 2019. Февраль № 1 (46). С. 69-76.

11. Мадгазин В.Прудон - Теория банка обмена / Livejournal. 16.11.2011. URL: https://vadimrm.livejournal. com/136086.html (дата обращения: 30.01.2021).

12. Маркс К., Энгельс Ф. Сочинения. Издание второе. Том 13.- М.: Государственное издательство политической литературы, 1959. 771 (XXVI) с.

13. Михаил Иванович Туган-Барановский. Пьер Жозеф Прудон / Его жизнь и общественная деятельность/ Глава V / sensusnovus. Цех социальной мысли. URL: https://www.sensusnovus.ru/analytics/2014/11/26/19795.html (дата обращения: 27.01.2021).

14. Моисеев С. Р. История центральных банков и бумажных денег.-М.: Вече, 2015. 536 с.

15. Оуэн Р. Избранные сочинения. Том I. Предшественники научного социализма / Под общ. ред. В.П.Волгина. - M. - Ленинград: Издательство Академии наук CCCP, MCML. 415 с.

16. Петухов Ю. В. Трудовые деньги или закат замкнутых самопровозглашенных республик / Мировой кризис хроника и комментарии. 20.06.2017. URL: http://worldcrisis.ru/crisis/2727858 (дата обращения: 27.01.2021).

17. Туган-Барановский М.И. Общественно-экономические идеалы нашего времени.- СПб.: Издательство «Вестника знания» (В.В.Битнера), 1913. 143 с.

18. Экономическая концепция Прудона. Особенности прудонизма как мелкобуржуазной идеологии / Vuzlit.ru. URL: https://vuzlit.ru/1842824/ekonomicheskaya_kontseptsiya_prudona (дата обращения: 06.02.2021). 